\title{
Application of Fe-Ni-W Plated Film Electrode to Zinc-Air Battery
}

\author{
Sachio Yoshihara*, Hikari Ohtake, Jiu Sasaki \\ Graduate School of Engineering, Utsunomiya University, Utsunomiya, Japan \\ Email: *sachioy@cc.utsunomiya-u.ac.jp
}

How to cite this paper: Yoshihara, S., Ohtake, H. and Sasaki, J. (2019) Application of Fe-Ni-W Plated Film Electrode to Zinc-Air Battery. Journal of Materials Science and Chemical Engineering, 7, 57-64. https://doi.org/10.4236/msce.2019.712007

Received: August 24, 2019

Accepted: December 17, 2019

Published: December 20, 2019

\begin{abstract}
This study was aimed at the preparation of an electrode for Zinc-air battery, which had excellent catalytic activity by use of electroplating of alloys made of abundant metal, such as Fe and Ni. The oxygen overvoltage of the Fe-Ni-W alloy plated electrode was the smallest through the measurement. The elemental composition and the enlargement of the surface area were confirmed by SEM and EDX analysis. Involvement of $\mathrm{Fe}$ and $\mathrm{W}$ of $\mathrm{Fe}-\mathrm{Ni}-\mathrm{W}$ alloy plated electrode will be one factor for its high catalytic activity. Thus plated Fe-Ni-W alloy electrodes were compared with other Fe alloy plated electrodes considering to their cathode performance as Zinc-air battery. The catalytic activity of Fe-Ni-W plated electrode showed the best performance comparing to Fe-Ni alloy plated electrodes as cathode for Zinc-air battery. Also comparing to the platinum electrode which had been widely used as cathode in the field of Zinc-air battery, the Fe-based alloy plated electrode showed better performance as the electrodes considering to its oxygen evolution reaction.
\end{abstract}

\section{Keywords}

Fe-Ni-W, Alloy, Electroplating, Zinc-Air Battery, Oxygen Evolution Reaction (OER)

\section{Introduction}

World energy consumption continues to increase along with economic growth, continuing to increase at an annual average of $2.6 \%$ from $1600 \mathrm{GJ}$ in 1965 , reaching $5300 \mathrm{GJ}$ in 2013. The main energy source responsible for this huge energy consumption will be fossil fuel. More than $80 \%$ of the current world energy demand is covered by natural gas, coal and oil. Disadvantages of the society consuming such a large amount of fossil fuel have emerged as global warming and environmental pollution problems. In order to solve this problem, 
conversion from fossil fuels to decarbonization and renewable energy, which is a low environmental load, should be a global issue [1] [2] [3]. For utilizing the renewable energy, energy storage system will be needed. Supposing electric energy as the second energy source, electric energy storage system will be indispensable.

Up to now, Li-ion batteries have been the most successful electric energy storage solution and widely used in portable electronics and electric vehicles (EVs). Unfortunately, their limitations of high cost, insufficient energy density, and poor safety have disturbed the large scale applications of Li-ion batteries in the automobile industry, especially for the extended range EVs. In this point, many post-lithium-ion technologies including $\mathrm{Na}-\mathrm{S}$ and metal-air batteries have been investigated. Recently, metal-air batteries have become a promising power source, based on the nature of high theoretical energy density and free-oxygen fuel from the atmosphere. Among various metal-air batteries, alkaline metal-air batteries, especially lithium-oxygen, have been intensively investigated due to their high specific energy density up to $5200 \mathrm{~W} \cdot \mathrm{h} \cdot \mathrm{kg}^{-1}$. However, the recharge ability, safety and cost issues make them hard to be commercialized. Because of these currently unconquerable limitations, rechargeable zinc-air batteries have attracted significant attention as an alternative in the past few years. As one of the most abundant elements in the earth's crust, zinc has been the chosen electrode material for several types of primary batteries ever since the past battery, e.g. Zinc-carbon battery. Primary zinc-air batteries were introduced to the science community in the late $19^{\text {th }}$ century, and their commercial products started to enter the market in the 1930s. Among all metal-air systems, zinc-air batteries are the most practically variable choice. They possess some desirable features such as a high theoretical energy density, low cost, great safety and environmental friendliness. The theoretical energy density of zinc-air is 1086 $\mathrm{W} \cdot \mathrm{h} \cdot \mathrm{kg}^{-1}$, about 5 times higher than that of Li-ion; its operational cost is estimated to be less than that of Li-ion. The primary zinc-air battery is a mature technology that has already been successfully applied to the fields of hearing, etc. Their recharge ability is realized by developing new bifunctional air cathodes and bifunctional oxygen electrocatalysts that can facilitate both the oxygen reduction reaction (ORR) during discharge and the oxygen evolution reaction (OER) during charge. Especially on bifunctional electrocatalysts for the air cathode, a comprehensive account of the current development status, challenges and possible solutions is highly necessary. Here in this paper, we focus on the fabrications of the air cathode of the electrically rechargeable and/or zinc-air batteries in alkaline electrolytes. We will propose newly developed air cathode of the rechargeable zinc-air battery, with higher bifunctional performance.

\section{Experimental}

\subsection{Method for Manufacturing Alloy Plated Electrode}

Stainless steel (SUS 430) which is relatively inexpensive and has good corrosion resistance was selected as a substrate to be subjected to electroplating treatment. 
It is general to apply nickel strike plating as a pretreatment to a plating material which is prone to generate an oxide film on the surface like stainless steel. Table 1 shows the plating conditions for nickel strike. The stainless steel substrate was degreased with acetone, followed with and distilled water, and then immersed in concentrated hydrochloric acid for 2 minutes to remove the oxide film. After washing above specimen with distilled water, Nickel strike plating was performed under constant current electrolytic method using an electrochemical measurement system (HA 305 Hokuto Denko Co., Ltd.) [4]. After that, masking was done so that the surface active area was $4 \mathrm{~cm}^{2}$ by use of masking tape (N-300 Nitto Denko Co., Ltd.).

Table 2, Table 3 show the bath composition and plating conditions for Fe-Ni alloy plating, Fe-Ni-W alloy plating, respectively. For the counter electrode, $\mathrm{Ni}$ electrode having sufficiently large surface area with respect to the cathode was used.

\subsection{Elemental, Crystal Structure Analysis and Surface Observation Method of Coated Surface}

The surface of the electrode was observed with a field emission scanning electron

Table 1. Bath composition and plating conditions for nickel-strike plating based on wood baths.

\begin{tabular}{ll}
\hline Bath composition & $\mathrm{mol} / \mathrm{dm}^{3}$ \\
\hline $\mathrm{NiCl}_{2}$ & $1.010 \mathrm{~mol} / \mathrm{dm}^{3}$ \\
$\mathrm{HCl}$ & $1.850 \mathrm{~mol} / \mathrm{dm}^{3}$ \\
\hline Plating Conditions & \\
\hline Current density & $100 \mathrm{~mA} / \mathrm{dm}^{2}$ \\
Plating period & $2 \mathrm{~min}$ \\
Bath temperature & $22^{\circ} \mathrm{C}-25^{\circ} \mathrm{C}$ \\
Counter electrode & Ni plate \\
\hline
\end{tabular}

Table 2. Bath composition and plating condition of Fe-Ni alloy plating.

\begin{tabular}{ll}
\hline Bath composition & $\mathrm{mol} / \mathrm{dm}^{3}$ \\
\hline $\mathrm{FeSO}_{4} \cdot 7 \mathrm{H}_{2} \mathrm{O}$ & 0.050 \\
$\mathrm{NiSO}_{4} \cdot 6 \mathrm{H}_{2} \mathrm{O}$ & 0.099 \\
$\mathrm{H}_{3} \mathrm{BO}_{3}$ & 0.243 \\
$\mathrm{C}_{2} \mathrm{H}_{8} \mathrm{O}_{7}$ & 0.026 \\
\hline Plating Conditions & \\
\hline Current density & $25 \mathrm{~mA} / \mathrm{dm}^{2}$ \\
Plating period & $20 \mathrm{~min}$ \\
Bath temperature & $40^{\circ} \mathrm{C}$ \\
pH & 2.50 \\
Counter electrode & Ni plate \\
\hline
\end{tabular}


Table 3. Bath composition and plating conditions for Fe-Ni-W alloy plating.

\begin{tabular}{ll}
\hline Bath composition & $\mathrm{mol} / \mathrm{dm}^{3}$ \\
\hline $\mathrm{FeSO}_{4} \cdot 7 \mathrm{H}_{2} \mathrm{O}$ & 0.04 \\
$\mathrm{NiSO}_{4} \cdot 6 \mathrm{H}_{2} \mathrm{O}$ & 0.08 \\
$\mathrm{Na}_{2} \mathrm{WO}_{4} \cdot 2 \mathrm{H}_{2} \mathrm{O}$ & 0.12 \\
$\mathrm{H}_{3} \mathrm{BO}_{3}$ & 0.16 \\
$\mathrm{C}_{2} \mathrm{H}_{8} \mathrm{O}_{7}$ & 0.02 \\
$\mathrm{C}_{6} \mathrm{H}_{5} \mathrm{Na}_{3} \mathrm{O}_{7} \cdot 2 \mathrm{H}_{2} \mathrm{O}$ & 0.19 \\
\hline $\mathrm{Plating}$ Conditions & \\
\hline Current density & $50 \mathrm{~mA} / \mathrm{dm}^{2}$ \\
Plating period & $30 \mathrm{~min}$ \\
Bath temperature & $75^{\circ} \mathrm{C}$ \\
pH & 7.3 \\
Counter electrode & Ni plate \\
\hline
\end{tabular}

microscope (FE-SEM, Hitachi Co. Ltd., S-4500). The surface condition was observed at an accelerating voltage of $15 \mathrm{kV}$.

For the purpose of qualitative and quantitative analysis of the surface, the evaluation by an energy dispersive X-ray analyzer (Horiba Co. Ltd., EMAX-5770) was carried out under the conditions of an acceleration voltage of $20 \mathrm{kV}$ and a probe current of $-0.2 \mathrm{nA}$.

Crystal structure analysis of samples by XRD (X-ray diffraction) were carried out by use of the horizontal-type multi-purpose X-ray diffractometer (Rigaku Co. Ltd., Ultima IV) under $\mathrm{CuK}_{\alpha}$ as X-ray source, $2 \theta / \mathrm{deg} 20^{\circ}-90^{\circ}$ of scanning range, $4^{\circ} / \mathrm{min}$ of scanning speed.

\subsection{Method and Conditions of Electrolysis Test}

LSV (linear sweep voltammetry) was carried out to evaluate the activity of the oxygen-evolution reaction, or the oxygen reduction reaction by use of electrochemical measurement system (Hokuto Denko Co. Ltd., HZ-5000). The electrolytic solution was $0.1 \mathrm{~mol} / \mathrm{dm}^{3} \mathrm{KOH}$ (industrial flaky $\mathrm{KOH}$ 95.5\%: Japan Soda Co. Ltd.) aqueous solution. Counter and reference electrode were Platinum mesh and SCE electrode, respectively. LSV measurement was carried out under room temperature $\left(25^{\circ} \mathrm{C}\right)$, potential sweep rate of $10 \mathrm{mV} / \mathrm{s}$.

Tafel plots, plots the logarithm of current density against electrode potential, were used for the analysis of oxygen evolution reaction mechanism. The exchange current density and Tafel slope could be obtained from the Tafel plots.

In the case of evaluation of oxygen reduction reaction, in advance $\mathrm{O}_{2}$ gas was bubbled in the solution for 30 minutes before LSV measurement, blank LSV were carried out also in the solution after bubbling $\mathrm{N}_{2}$ for 30 minutes.

Real oxygen reduction current were estimated by taking the difference between the current measured after $\mathrm{O}_{2}$ bubbling and that measured after $\mathrm{N}_{2}$ bubbling. 


\section{Results and Discussions}

\subsection{Surface Analysis of Fe-Ni and Fe-Ni-W Alloy Plated Film}

The surface composition analysis of alloy plating films using EDX results were shown in Table 4. It was confirmed that each films were made of metals contained in each plating bath.

Figure 1 shows SEM images of $\mathrm{Fe}-\mathrm{Ni}, \mathrm{Fe}-\mathrm{Ni}-\mathrm{W}$ plated films. The surface of $\mathrm{Fe}-\mathrm{Ni}$ was smooth, on the other hand that of $\mathrm{Fe}-\mathrm{Ni}-\mathrm{W}$ were consisted of a number of small grains.

XRD analysis of crystal structure was shown in Figure 2. According to the results of the $\mathrm{Fe}-\mathrm{Ni}-\mathrm{W}$, broadband $45^{\circ}$ peak suggested the amorphous-like structure. Obtained crystallite grain size by Scherrer equation were $2.93 \mathrm{~nm}, 12.3$ $\mathrm{nm}$ for $\mathrm{Fe}-\mathrm{Ni}$-W, Fe-Ni plated films, respectively. The crystallite size of Fe-Ni-W was smaller than that of $\mathrm{Fe}-\mathrm{Ni}$.

\subsection{Electrolytic Test}

LSV measurements of oxygen evolution reaction were shown in Figure 3. LSV

Table 4. Elemental analysis of alloy plating films (wt\%).

\begin{tabular}{cccc}
\hline & $\mathrm{Fe}$ & $\mathrm{Ni}$ & $\mathrm{W}$ \\
\hline Fe-Ni & 70.0 & 30.0 & - \\
Fe-Ni-W & 28.0 & 27.6 & 44.4 \\
\hline
\end{tabular}
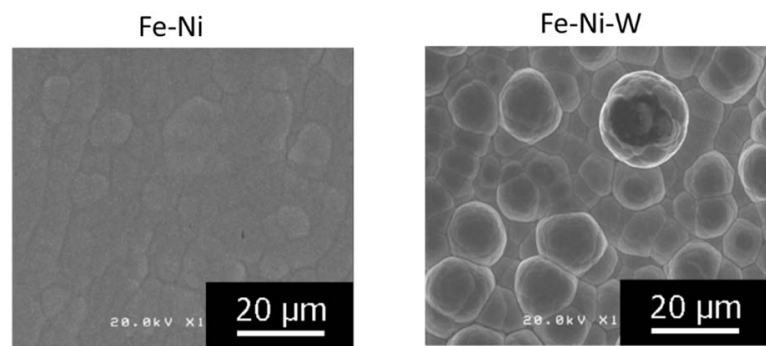

Figure 1. SEM photopraphs.

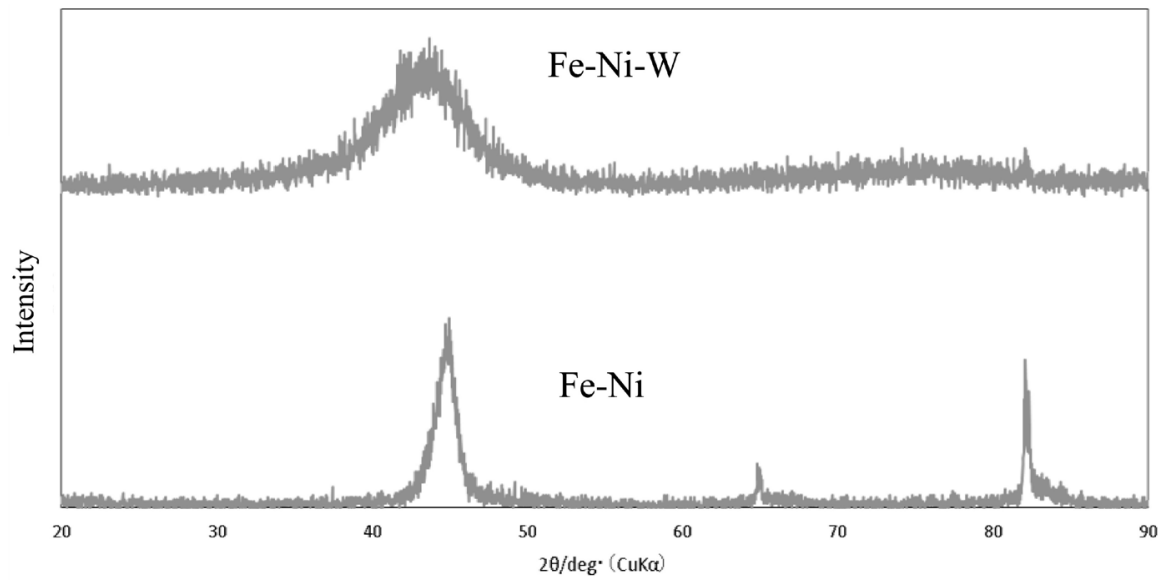

Figure 2. XRD chart. 
for Pt plate were also shown for comparison. Comparing current density at the same potential, Fe-Ni-W showed the largest current and Pt showed the lowest. Fe-Ni-W showed the highest activity for oxygen evolution reaction [5].

Tafel plot analysis results were shown in Figure 4. Tafel slope and exchange current density calculated from these Tafel plots were shown in Table 5. It was suggested that $\mathrm{Fe}-\mathrm{Ni}-\mathrm{W}$ showed relatively high activity for oxygen evolution reaction.

The Tafel slope suggested the rate determining step (rds) for oxygen evolution

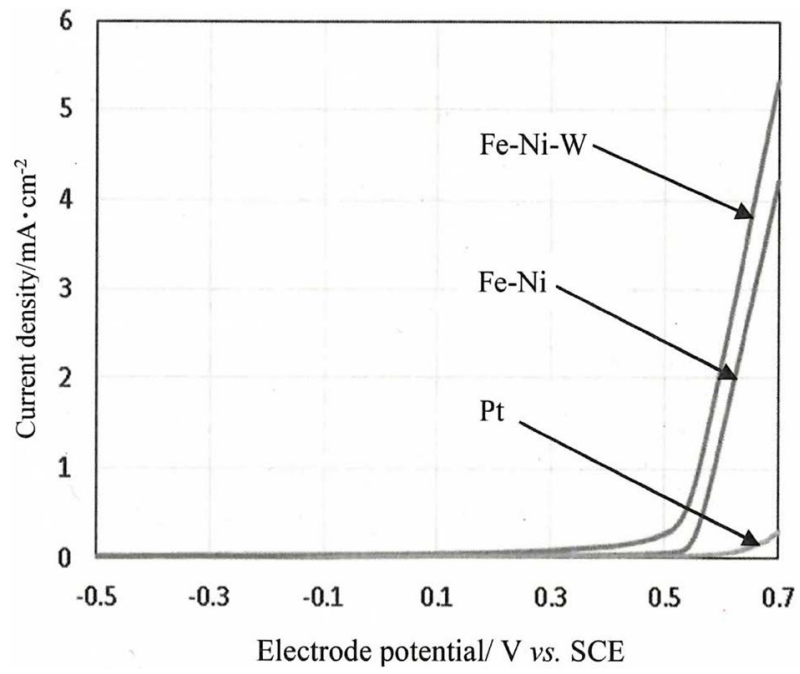

Figure 3. LSV for OER.

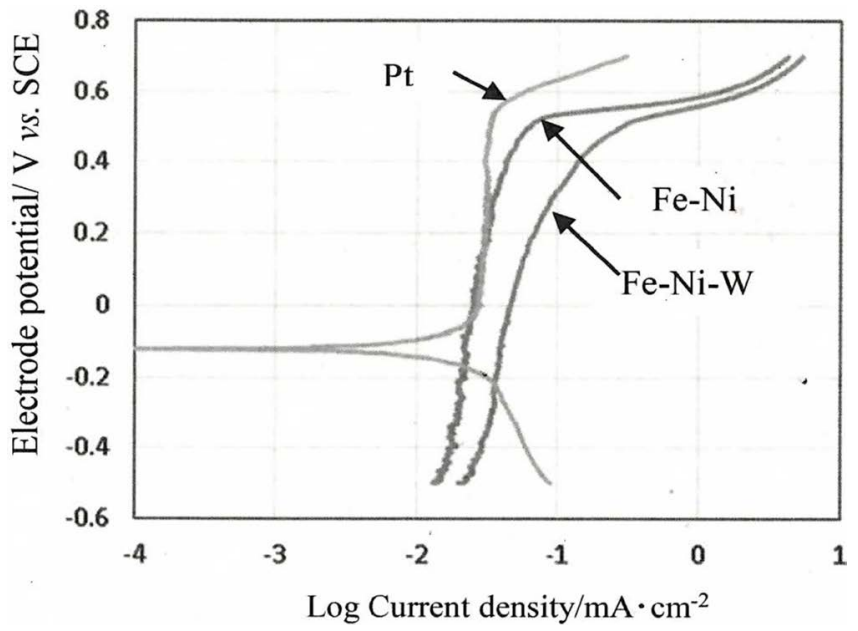

Figure 4. Tafel plots.

Table 5. Summarized Tafel data.

\begin{tabular}{ccc}
\hline & Tafel slope $[\mathrm{mV} / \mathrm{dec}]$ & Exchange current density $\left[\mathrm{mA} / \mathrm{cm}^{2}\right]$ \\
\hline Fe-Ni-W & 89.4 & 0.19 \\
$\mathrm{Fe}-\mathrm{Ni}$ & 64.7 & 0.08 \\
$\mathrm{Pt}$ & 130.5 & $1.03 \times 10^{-4}$ \\
\hline
\end{tabular}


reaction on each electrode. These could be classified into four groups. The Tafel slope value for each rds step were summarized as follows,

$$
\begin{aligned}
& 120 \mathrm{mV} / \mathrm{dec} \mathrm{M}+\mathrm{OH}^{-} \rightarrow \mathrm{M}-\mathrm{OH}_{\mathrm{ads}}{ }^{*}+\mathrm{e}^{-} \\
& 60 \sim 120 \mathrm{mV} / \mathrm{dec} \mathrm{M}-\mathrm{OH}_{\mathrm{ads}}{ }^{*} \rightarrow \mathrm{M}^{-} \mathrm{OH}_{\mathrm{ads}} \\
& 40 \sim 60 \mathrm{mV} / \mathrm{dec} \mathrm{M}-\mathrm{OH}_{\mathrm{ads}}+\mathrm{OH}^{-} \rightarrow \mathrm{M}^{-\mathrm{O}_{\mathrm{ads}}}+\mathrm{H}_{2} \mathrm{O}+\mathrm{e}^{-} \\
& 30 \sim 40 \mathrm{mV} / \mathrm{dec} \mathrm{M}-\mathrm{O}_{\mathrm{ads}} \rightarrow \mathrm{M}+1 / 2 \mathrm{O}_{2}
\end{aligned}
$$

The rds step for OER on Fe-Ni, Fe-Ni-W electrode will be (B) process, on the other hand that on Pt will be (A) process. On platinum electrode $\mathrm{OH}^{-}$adsorption activity for oxygen evolution reaction is inferior to that of $\mathrm{Fe}-\mathrm{Ni}-\mathrm{W}$ or $\mathrm{Fe}-\mathrm{Ni}$. On Fe-Ni-W or Fe-Ni electrode $\mathrm{OH}^{-}$could adsorp easier to platinum. But it takes much time to form "stable" $\mathrm{M}-\mathrm{OH}$ ads from "instable" $\mathrm{M}-\mathrm{OH}_{\text {ads }}{ }^{*}$. In addition, visual observation confirmed that more oxygen bubbles on Pt electrode remained on the surface under operation comparing to that of $\mathrm{Fe}-\mathrm{Ni}-\mathrm{W}$ or Fe-Ni. Such easy release of evolved oxygen bubbles might be one reason for high activity for oxygen evolution reaction on Fe-Ni-W or Fe-Ni electrode. SEM observation suggested that $\mathrm{Fe}-\mathrm{Ni}-\mathrm{W}$ plated electrode had rough surface (increase of the surface area) comparing to that of $\mathrm{Fe}-\mathrm{Ni}$, it might be one reason for high activity for oxygen evolution reaction on Fe-Ni-W.

LSV for the oxygen reduction reaction were shown in Figure 5. LSV for Pt plate was also shown for comparison. Comparing the current density at the same potential, Pt showed the largest reduction current. Also, the onset potential for reduction current on the iron-plated electrode were less noble to that of Pt plate electrode. The interface between vapor and liquid and solid-phase is important for oxygen reduction reaction. This suggests that the reason of decreased activity of the iron-plated electrode will be due to poor affinity between Fe-alloy and $\mathrm{O}_{2}$. As mentioned above it was confirmed that more oxygen bubbles on Pt electrode remained on the surface under oxygen evolution reaction. This suggests that the affinity between $\mathrm{Pt}$ and $\mathrm{O}_{2}$ will be stronger comparing to that between $\mathrm{Fe}$-alloy

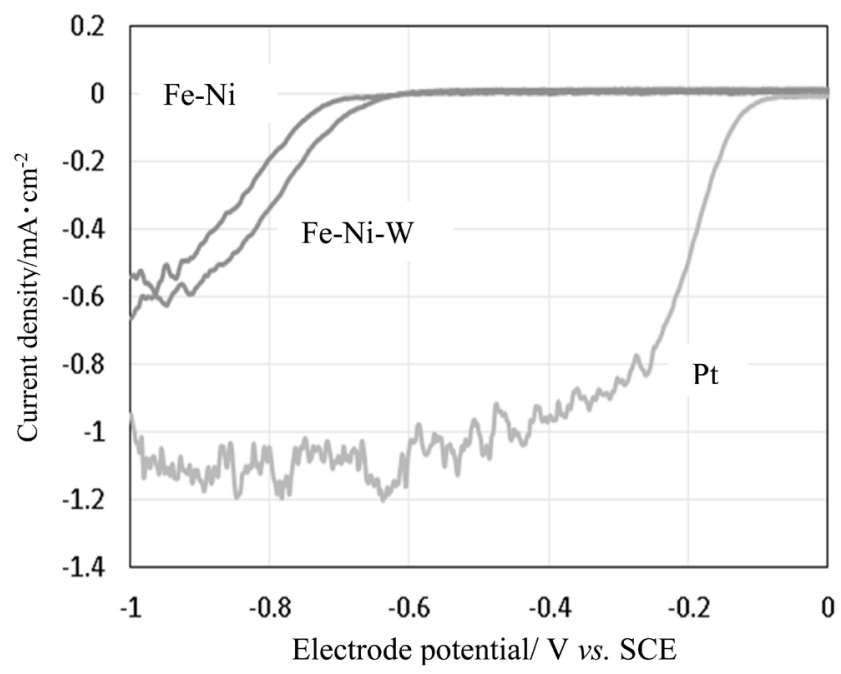

Figure 5. LSV for ORR. 
and $\mathrm{O}_{2}$. So such a well formed three-phase surface in the case of Pt electrode could reduce the dissolved oxygen in electrolyte. On the other hand quick release of $\mathrm{O}_{2}$ on the $\mathrm{Fe}$-alloy electrode induced large overpotential, small current density. Oxygen reduction reaction mechanism has not been cleared in detail, but oxygen-metal coupling strength will be due to the strength of covalent bonds of the $2 \mathrm{p}$ orbital of oxygen and metal d-orbital. W (tungsten) having $5 \mathrm{~d}$ orbital electron as well as Pt leads to dissociative adsorption of oxygen molecules so the activity of Fe-Ni-W was superior to that of Fe-Ni.

\section{Conclusions}

This study was aimed at the preparation of the air cathode for Zinc-air battery, which had excellent catalytic activity by use of electroplating of alloys made of abundant metal, such as Fe and Ni. Finally iron based alloy plated electrodes, especially Fe-Ni-W plated electrode were highly active for oxygen evolution reaction in compared to $\mathrm{Pt}$ from the results of the exchange current density obtained from LSV measurement, Tafel plots. The iron-based alloy coated electrode tends to be adsorbed by $\mathrm{OH}^{-}$species, successively release the evolved oxygen away from the surface, thus improves the oxygen evolution reaction activity. SEM, XRD observations revealed that Fe-Ni-W plated electrode, having increased surface area caused by the roughness of it, had a fine crystalline structure than that of the Fe-Ni. In the present study, considering to the oxygen reduction activity, comparing to Pt, iron-plated electrode showed a smaller current density and high overvoltage for oxygen reduction reaction. It will be attributed to poor forming of good critical gas/liquid/solid interface between oxygen reduction in aqueous solution. In addition, oxygen-metal coupling strength will be due to the strength of covalent bonds of the $2 \mathrm{p}$ orbital of oxygen and metal d-orbital. W (tungsten) having $5 \mathrm{~d}$ orbital electron as well as Pt leads to dissociative adsorption of oxygen molecules so the activity of $\mathrm{Fe}-\mathrm{Ni}-\mathrm{W}$ was superior to that of Fe-Ni.

Further study of the iron-plated electrode for oxygen reduction reaction will be needed for the practice use of such an electrode as the air cathode for metal-air batteries.

\section{Conflicts of Interest}

The authors declare no conflicts of interest regarding the publication of this paper.

\section{References}

[1] Denkikagaku, A. (2002) ECSJ Ed., Baifukan.

[2] NEDO Suiso Enerugii Hakusho (2015) NEDO Ed.

[3] Dresselhaus, M. and Thomas, I. (2001) Nature, 414, 332.

[4] Mekkigijyutu, S. (2011) Kantogakuin Univ. Ed., Maruzen.

[5] Tong, Y., Yu, X. and Shi, G. (2017) Phys. Chem. Chem. Phys., 19, 4821-4826. 